\title{
Operative management of acetabulum fractures in the obese patient: challenges and solutions
}

This article was published in the following Dove Press journal:

Orthopedic Research and Reviews

7 August 2017

Number of times this article has been viewed

\section{Neil R Sardesai \\ Michael A Miller \\ Julio J Jauregui \\ Cullen K Griffith \\ R Frank Henn 3rd \\ Jason W Nascone}

Department of Orthopedics, University of Maryland School of

Medicine, Baltimore, MD, USA
Correspondence: Jason W Nascone Department of Orthopedics, University of Maryland School of Medicine,

I I 0 S. Paca Street, 6th Floor, Suite 300,

Baltimore, MD 2I20I, USA

$\mathrm{Tel}+\mathrm{l} 4103283179$

Email jnascone@umoa.umm.edu
Abstract: In this review, we aim to increase our knowledge of the treatment of acetabular fractures in the obese patient population. The extremely high incidence of obesity in the USA is a looming health care concern that impacts aspects of health care in all medical specialties. There are specific concerns to the orthopedic surgeon when treating obese patients for acetabular fracture. Patients with body mass index $\geq 30$ present particular challenges to the surgeon in terms of preexisting medical conditions, diagnostic imaging, and perioperative complications. Specifically, this patient population experiences worse functional outcomes and greater incidence of surgical site infection, intraoperative blood loss, deep venous thrombosis, post-traumatic osteoarthritis, heterotopic ossification, and increased hospital length of stay. These problems are further exacerbated in the morbidly obese, as a scaling effect exists between increasing body mass index and worsening complication profile. This is problematic given the current high incidence of morbid obesity in the USA and particularly worrisome in light of the projected increase in obesity rates for the future. Keywords: hip fractures, obesity, BMI, morbidly obese, morbid obesity, diagnostic imaging, perioperative complications, functional outcomes, super-obesity, surgical comorbidities, cost, ORIF

\section{Introduction}

With an incidence of $\sim 3$ out of every 100,000 patients per year, acetabular fractures are among the more challenging injuries presented to the orthopedic surgeon. ${ }^{1}$ These challenges can be further increased in an obese patient. Presently, at least $35 \%$ of American adults aged $\geq 20$ years are obese, ${ }^{2}$ and current trends estimate that by 2030 , obesity rates may increase to $51 \% .^{3}$ Additionally, morbid obesity (body mass index $[\mathrm{BMI}] \geq 40$ ) and super-obesity (BMI $\geq 50$ ) quadrupled and quintupled in prevalence, respectively, between 1986 and $2000 .^{4}$

Obesity reduces life expectancy and is associated with numerous medical and surgical comorbidities. ${ }^{5}$ Obesity increases the rate of perioperative complications regardless of injury, and postoperative mortality and morbidity rates are higher in obese patients. ${ }^{6-11}$ Furthermore, obesity is associated with an increased likelihood of wound dehiscence, increased hospital length of stay, and postoperative respiratory complications. ${ }^{7,8,12}$

As the rate of obesity in this country continues to rise, the need for well-defined literature guiding the fracture management in this patient population grows. The goal of this review is to identify the challenges that this specific patient population presents to the orthopedic surgeon in terms of patient characteristics, diagnosis, treatment, complications, and cost, with the hope to provide solutions in the management of acetabulum fractures in an obese patient. 


\section{Methods}

An electronic database search was conducted to evaluate the current MEDLINE, EMBASE, and Ovid electronic databases for articles published before July 2016 relevant to acetabular fracture in the obese patient population. Articles published in languages other than English were excluded. The initial search strings utilized the Boolean "obes*" AND "acetabul*" AND "fract*", which returned a total of 49 articles. These articles were then cross-referenced, which provided 39 additional sources. After reviewing all 88 articles, it was determined that only 29 studies were of high importance to our topic. High importance was defined as studies that provided sufficient information on surgical management, complications, and outcomes of the treatment of acetabular fractures in obese patient population. We defined obesity based on a BMI $\geq 30$, which is calculated by dividing a patient's weight in kilograms by the square of their height in meters $\left(\mathrm{kg} / \mathrm{m}^{2}\right)$.

\section{Results}

\section{Patient characteristics}

Acetabular fractures generally have a bimodal distribution with respect to age. The first peak represents fractures in young adults that result from high-energy trauma, while the second peak is in the elderly population who sustain fractures from low-energy mechanisms. ${ }^{13}$ Historically, these injuries have occurred more frequently in males than females, but this trend is slowly changing as females are representing a more balanced share of acetabular fractures. ${ }^{1,13}$

Recently published data show that, in the setting of rising national obesity rates, the age-adjusted prevalence of obesity is $5.4 \%$ higher in women $(40.4 \%)$ than men (35.0\%), and for patients with $\mathrm{BMI} \geq 40$, the rate in women $(9.9 \%)$ is almost double that in men $(5.5 \%) \cdot{ }^{14}$ On a whole, these trends suggest that orthopedic surgeons could manage more cases of acetabular fracture in the elderly, the obese, and female populations in future years.

A study by Karunakar et al showed the prevalence of obesity (BMI $\geq 30$ ) and morbid obesity (BMI $\geq 40$ ) in acetabular fracture patients treated with open reduction and internal fixation (ORIF) at a level-1 trauma center to be $44 \%$ and $12 \%$, respectively ( $\mathrm{N}=169$ patients). ${ }^{11}$ Another more recent study demonstrated that the obesity (BMI $\geq 30$ ) and morbid obesity $(\mathrm{BMI} \geq 40)$ rates in displaced acetabular fracture patients treated with ORIF were $38 \%$ and $9 \%$, respectively ( $\mathrm{N}=242$ patients). ${ }^{15}$

\section{Diagnosis}

Radiographic assessment of the acetabulum can also be more challenging in obese populations. Larger soft tissue envelops increase X-ray scattering and decrease penetration, leading to low image contrast. ${ }^{16}$ To combat this, Bucky grids can be employed to reduce scatter, and increasing $\mathrm{kV}$ peak and $\mathrm{mA}$ improves X-ray penetration and hastens development speed, which boost image quality. ${ }^{16}$ All of these methods that provide better visualization in obese patients have the effect of significantly increasing the effective radiation dose to the patient. ${ }^{17}$

More practical barriers can also be encountered when imaging the obese. Standard X-ray cassette sizes may not be large enough to obtain a full view of the pelvis on a single image. Patient obesity also makes positioning to obtain proper Judet views more difficult. ${ }^{18}$ Intraoperative pelvic imaging using $\mathrm{C}$ arm fluoroscopy can be very difficult in patients with a large pannus, particularly with inlet views. Bowel gas, intravenous contrast, and parenteral contrast may also impede traditional imaging techniques. Also, some computed tomography (CT) scanners have girth limits and weight restrictions of $200 \mathrm{~kg} .{ }^{6}$ If patients exceed those limits, imaging may require transfer to another medical facility with extra-large scanners. Hence, veterinary schools or zoos could be utilized. ${ }^{19}$

While conventional radiographs are usually sufficient to characterize acetabular fracture type, CT imaging can capture the degree of articular comminution and impaction often present in these injuries. ${ }^{20,21}$ As described by O'Toole et al, CT scans may provide higher accuracy when evaluating these fractures and with higher interobserver reliability. ${ }^{22}$ Further, CT scans eliminate the adverse imaging effects of adipose tissue and bowel, and they are as useful as plain radiographs for classifying acetabular fractures in obese patients. ${ }^{23}$

\section{Complications}

In a seminal investigation conducted in 2003, Mears et al published a retrospective study about indicators of outcome for 411 consecutive, displaced acetabular fractures managed operatively. ${ }^{10}$ Of the 42 morbidly obese patients, 22 (53\%) had fair or poor clinical results as determined by Harris hip score, which was significantly greater than the 97 other fair or poor clinical results out of 369 (26\%) nonmorbidly obese population in the study $(P<0.001) .{ }^{10} \mathrm{Also}$, all of the 10 deep, intra-articular wound infections occurred in morbidly obese patients subjected to extensile exposures and, in a similar way, all 13 of the Brooker Grade III and IV heterotopic bone ossification occurrences were in morbidly obese patients. ${ }^{10}$

Porter et al conducted a retrospective study of 41 morbidly obese (BMI $\geq 40$ ) and 394 non-morbidly obese (BMI <40) patients who had operatively repaired acetabular fractures. ${ }^{12}$ 
Postoperative complications and other variables such as intraoperative blood loss, operative time, and positioning time were assessed in the two groups. ${ }^{12}$ The morbidly obese group required longer average positioning time, statistically significantly greater operative time, and longer hospital lengths of stay than the non-morbidly obese group. ${ }^{12}$ Additionally, there were notably more total complications in the morbidly obese population than in the non-morbidly obese group, and the relative risk of complication in the morbidly obese group was 2.6 times that of the non-morbidly obese. ${ }^{12} \mathrm{~A}$ significant difference was also appreciated in the development of wound healing complications. Morbidly obese patients were more likely to have wound healing complications, with the majority requiring operative debridement and irrigation of their wounds. ${ }^{12}$ Furthermore, the morbidly obese group experienced a higher percentage of deep vein thrombosis (DVT), pulmonary embolism, sciatic or femoral nerve palsy, implant or fixation failure, symptomatic heterotopic ossification (HO), and death relative to the non-morbidly obese group; however, as these outcomes were individually rarer events, statistical significance was not observed. ${ }^{12}$

When BMI, measured as a continuous variable, was examined as a predictor of complications after ORIF for acetabular fracture, a significant relationship was found with DVT, wound infection, and surgical blood loss. ${ }^{11}$ Further, the odds ratio for DVT was 2.6 times greater in obese than normal weight patients, and the odds ratio for wound infection was 5 times larger for morbidly obese patients. ${ }^{11}$

A retrospective analysis of 244 high-energy acetabular and pelvic fracture patients supported previous studies showing longer hospitalizations and higher complication rates in the morbidly obese patient population compared to nonobese patients..$^{24}$ Obesity was demonstrated to be a significant risk factor for early complication in both the operatively and nonoperatively treated acetabular fracture groups; however, the sample size for this study was not large enough to show significance for any specific complication. ${ }^{24}$ Risk was also shown to be scaled to BMI, with morbidly obese patients faring even worse than the obese group. ${ }^{24}$

A strong connection exists between surgical wound infections and obesity. In a retrospective analysis of risk factors of surgical site infection (SSI) after ORIF of acetabular fracture involving 326 patients, BMI was found to have a highly significant association with SSI. ${ }^{25}$ A 2015 Chinese study of similar size and methodology found the same result. ${ }^{26} \mathrm{An}$ early study of 131 displaced acetabular fractures treated with ORIF found that four of the seven major wound issues occurred in morbidly obese patients (five obese patients total), suggesting a link between SSI and obesity. ${ }^{27}$ Another study that investigated risk factors for the development of deep postoperative wound infection following ORIF of acetabular fractures showed a significantly higher rate of obesity in the infected versus noninfected groups. ${ }^{28}$

In addition to SSI, obese patients experience other unique surgical site complications. A study by Lawyer et al demonstrated that morbidly obese patients are more likely to develop post-traumatic osteoarthritis following acetabular fixation..$^{29}$ Twenty-six out of 38 morbidly obese patients (68\%) developed post-traumatic arthritis out of a series of 299 acetabular fixations. ${ }^{29}$ A retrospective study comparing the incidence of $\mathrm{HO}$ after operative treatment of acetabular fracture in morbidly obese patients (BMI $>40$ ) compared to those patients with a BMI $\leq 40$ showed that only $18 \%(68 / 374)$ of nonobese patients developed HO, while 47\% (21/45) of morbidly obese patients developed HO. ${ }^{30}$

Another study also retrospectively examined morbidly obese (BMI $\geq 35$ ) and non-morbidly obese (BMI <35) patients with traumatic acetabular fractures. ${ }^{31}$ It was reported that morbidly obese patients required longer positioning and operative times than non-morbidly obese patients. ${ }^{31}$ However, the study did not show worse perioperative outcomes in the morbidly obese group. ${ }^{31}$ The lack of statistically significant differences in perioperative outcomes may be a result of limited sample size, because the morbidly obese group consisted of only 20 patients. $^{31}$

The overarching theme in the literature is that obese patients have worse complications following surgical management of acetabular fracture, compared to nonobese patients. Broadly, obese patients undergoing ORIF of acetabular fractures have worse clinical results, as given by Harris hip scores, ${ }^{10}$ and experience higher postoperative complication rates. ${ }^{11,12,24} \mathrm{SSI}$ is a particularly common complication in this population. ${ }^{10-12,25-28}$ Other specific perioperative complications seen more frequently in this population are increased intraoperative blood loss, higher rate of DVT occurrence, and increased hospital length of stay. ${ }^{11,12,24}$ Several studies have also noted increased incidence of post-traumatic osteoarthritis and $\mathrm{HO}$ in the obese population. ${ }^{10,29,30}$

\section{Costs and other considerations}

Obesity is becoming an increasingly important factor in the cost of health care. In the USA, almost 150 billion dollars per year is attributable to obesity-related expenditures in health care, and obese adults have $36 \%$ higher annual medical expenditures than their normal-weight peers. ${ }^{3,32,33}$ A higher incidence of comorbidities, including diabetes mellitus, 
stroke, hypertension, coronary artery disease, many cancers, and respiratory disorders, is present in obese adults. ${ }^{7}$

Complications from both medical comorbidities and those complications investigated in detail in the previous section can affect the health experience of obese adults receiving surgical treatment for acetabular fracture. As medical management of adverse events incurs costs, it can be anticipated that cost of care would be higher in a patient population that experiences more complications. Of the specific complications discussed in the prior section, increased hospital length of stay is likely to have direct impact on cost of care. ${ }^{12,24}$ SSIs and delayed wound healing are major complications of ORIF of acetabular fracture in the obese. ${ }^{11}$ The burden of costs associated with treatment of these complications is significant. Prolonged hospitalization, return to the operating room, and long-term antibiotics could drive cost upward. Other indirect contributors to increased cost might be the initial and subsequent management of DVT, post-traumatic arthritis, and HO, which present more frequently in obese patients. ${ }^{10,29,30}$

Managing obese patients requires more physical resources as well. Successful surgery often relies on additional assistants to aid in soft tissue retraction. Depending on their level of obesity, patients may require larger scanners, special operating tables, the rigging of two tables together, and special surgical equipment such as retractors and guides in obese sizes.

\section{Perioperative issues}

\section{Treatment}

The approach and principles to surgical management of fractures of the acetabulum in patients who are obese are the same as those of nonobese. Appropriate fracture reduction, articular surface congruity, and stability must be achieved.

Obesity is an independent risk factor for cardiovascular disease, which increases the risk of perioperative complications. $^{34-36}$ Perioperative resuscitation of morbidly obese patients is of crucial importance. Patients undergoing fixation of acetabular fractures frequently endure significant amounts of blood loss. Patients who are morbidly obese have increased cardiac outputs proportional to their increased size. Large blood loss associated with preexisting increased cardiac output can overload the heart and increase the mortality risk for the patient. ${ }^{37-39}$

In addition to cardiac risks, obese patients have significant pulmonary morbidity associated with surgery. Obese patients have a significant difficulty ventilating, especially when under anesthesia, because of their increased chest wall size, weak muscles of respiration, and decreased lung compliance. ${ }^{35,40,41}$ Their size puts them at increased risk for pneumonitis, atelectasis, and aspiration pneumonia.

Obesity increases the risk for developing insulin resistance and type two diabetes. ${ }^{42}$ Complications and fracture outcomes are worse in diabetic patients compared with normoglycemic individuals, and hyperglycemia in the perioperative period, specifically, has been shown to raise surgical complication risk. ${ }^{43,44}$

Surgical approach and patient positioning are most commonly determined by fracture pattern. It is important to recognize that positions which restrict chest and abdominal motion can compromise ventilation and are poorly tolerated by obese patients. ${ }^{18}$ The supine and prone positions can result in compression of the vena cava and the aorta as well as compression of the diaphragm, making ventilation more difficult. ${ }^{35}$ The lateral decubitus is best tolerated by obese patients, because the weight of the panniculus is off the abdomen, allowing for greater diaphragmatic excursion. The lateral position might also prove beneficial at the surgical site as gravity pulls the excess soft tissues away improving access to the acetabulum; however, this position can pose a problem when attempting reduction, because of the medialization of the femoral head due to the weight of the leg. ${ }^{35,45}$

There has been an overall increase in the incidence of total hip arthroplasty as a treatment modality for patients with acetabular fractures. ${ }^{46,47}$ Current literature demonstrates reasonable functional outcomes in elderly osteoporotic acetabular fractures. ${ }^{48}$ There is a paucity of literature demonstrating outcomes of this treatment modality in obese patients.

Despite the challenges of operating in a deeper hole, no difference has been found in the ability to achieve adequate reduction between those who are of normal weight and those who are morbidly obese. ${ }^{18}$ Porter et al investigated obese $(\mathrm{BMI} \geq 30)$ and nonobese patients $(\mathrm{BMI}<30)$ treated with ORIF for displaced acetabular fracture who were evaluated for reduction quality by radiograph and CT. ${ }^{15}$ Importantly, their study showed no statistically significant difference in reduction quality between either the obese group (93 patients) and the nonobese group (149 patients) or the morbidly obese group (BMI $\geq 40 ; 21$ patients) and the non-morbidly obese patients (BMI $<40 ; 221$ patients) based on BMI. ${ }^{15}$ It is important to note that to achieve exposure and reduction, alternative retractors and reduction clamps might be necessary.

\section{Discussion}

Obesity is a complex disease that causes significant pathophysiologic and anatomic changes to the patient. These 
changes can be seen across a spectrum of patients, and it is therefore important that obesity is clearly defined. All of the literature currently reviewed defines obesity in terms of BMI. Within this definition, BMI is discussed as a continuous variable, a categorical variable (overweight, obese, morbidly obese), and a binary variable. Category cutoffs are not always assigned in a uniform way. In addition, BMI does not account patients with increased muscle to fat ratios, which mathematically give them greater BMIs that may incorrectly assign them to the obese category. ${ }^{49}$ Given the imperfect definition of obesity using BMI, the question arises as to what is the most clinically meaningful way to define obesity.

The observation of a scaling effect of BMI suggests that a binary definition might not be the most effective. Karunakar et al found that higher BMI confers greater risk of complications and adverse outcome for obese patients undergoing ORIF for acetabular fracture. They showed a significant direct relationship of increased estimated blood loss, SSI, and DVT occurrence with higher BMI measured as a continuous variable. ${ }^{11}$ Other studies that used categorical definitions of obesity reported similar findings in which obese patients do worse than healthy weight patients but not as poorly as morbidly obese patients. ${ }^{24}$ This demonstrates that continuous and categorical BMI data show an important trend that may seem intuitive; the higher the BMI is above a threshold denoting obesity, the worse is the surgical risk and the outcome profile.

It is well established that obese trauma patients may have elevated mortality and morbidity rates. ${ }^{9,50-52}$ Obese patients experience an increase in infection rates and overall complication rates. Obese patients have a higher probability of requiring mechanical ventilation, experiencing multisystem organ failure, wound complications, longer length of stay in the intensive care unit, and increased perioperative and postoperative complications. , $^{8-12,24-30,52-55}$ In addition to increased complication rates, obese patients undergoing ORIF of acetabular fractures may have worse postoperative functional results and clinical outcomes. ${ }^{10}$

Often, studies of perioperative complications in this patient population are not powered to examine topics far beyond total complication rate, such as pulmonary embolism and sciatic or femoral nerve palsy. A meta-analysis could be a helpful technique to examine these less-common outcomes. Areas in which conflicting results exist, such as obesity's effect on operative time, positioning, and blood loss, might be made clearer through meta-analysis.

Knowledge of the increased risks facing obese patients undergoing ORIF of an acetabular fracture is important, but the lack of experimental studies on this population leaves surgeons without strong guidance to mitigate those risks. Further experimental research can help surgeons better manage the expected complications.

As obesity continues to rise in the USA, we can only expect to see more obese patients requiring surgical treatment of acetabular fractures. While acetabular fractures resulting from high-energy mechanisms are far more common in younger males, the trend is slowly shifting to include more elderly, more female, and more obese patients. Diagnostic imaging of acetabular fractures can be more challenging in the morbidly obese patients, even with the use of CT as scanners have weight and size limits. When considering surgical technique, patient positioning and surgical approach should also be determined by fracture pattern, although patient obesity may present difficulties with ventilation, resuscitation, and decubitus ulcers. Last, while it is understood that obesity lays a greater financial burden on health care in the USA, it does not change reimbursement for treating morbidly obese patients undergoing surgical fixation of acetabular fractures compared to normal-weight patients. In addition, the use of the Current Procedural Terminology Modifier 22 code has not been shown to change mean reimbursement for the morbidly obese patients surgically treated for acetabular fracture. ${ }^{27}$

\section{Conclusion}

Obese patients represent a unique set of challenges compared with their nonobese counterparts. The orthopedic community should be aware of this in light of the projected rise in American obesity rates. In the future, the need for studies examining practical ways in which the complication profile can be decreased in this population is vital.

\section{Acknowledgment}

This manuscript submitted represents original work and has not been previously published or simultaneously submitted elsewhere for publication.

\section{Author contributions}

All authors contributed toward data analysis, drafting and revising the paper and agree to be accountable for all aspects of the work.

\section{Disclosure}

All authors have provided full disclosure regarding any relevant relationships, financial, and otherwise. All authors report no conflicts of interest in this work. 


\section{References}

1. Laird A, Keating JF. Acetabular fractures: a 16-year prospective epidemiological study. J Bone Joint Surg Br. 2005;87(7):969-973.

2. Scherer PE, Hill JA. Obesity, diabetes, and cardiovascular diseases: a compendium. Circ Res. 2016;118(11):1703-1705.

3. Wang Y, Beydoun MA, Liang L, Caballero B, Kumanyika SK. Will all Americans become overweight or obese? estimating the progression and cost of the US obesity epidemic. Obesity (Silver Spring). 2008;16(10): 2323-2330.

4. Sturm R, Hattori A. Morbid obesity rates continue to rise rapidly in the United States. Int J Obes (Lond). 2013;37(6):889-891.

5. Pender JR, Pories WJ. Epidemiology of obesity in the United States. Gastroenterol Clin North Am. 2005;34(1):1-7.

6. Sabharwal S, Root MZ. Impact of obesity on orthopedics. J Bone Joint Surg Am. 2012;94(11):1045-1052.

7. Abir F, Bell R. Assessment and management of the obese patient. Crit Care Med. 2004;32(Suppl 4):S87-S91.

8. Whiting PS, White-Dzuro GA, Avilucea FR, et al. Body mass index predicts perioperative complications following orthopedic trauma surgery: an ACS-NSQIP analysis. Eur J Trauma Emerg Surg. 2017;43(2): 255-264.

9. Byrnes MC, McDaniel MD, Moore MB, Helmer SD, Smith RS. The effect of obesity on outcomes among injured patients. J Trauma. 2005;58(2): 232-237.

10. Mears DC, Velyvis JH, Chang CP. Displaced acetabular fractures managed operatively: indicators of outcome. Clin Orthop Relat Res. 2003; 407:173-186.

11. Karunakar MA, Shah SN, Jerabek S. Body mass index as a predictor of complications after operative treatment of acetabular fractures. J Bone Joint Surg Am. 2005;87(7):1498-1502.

12. Porter SE, Russell GV, Dews RC, Qin Z, Woodall J Jr, Graves ML. Complications of acetabular fracture surgery in morbidly obese patients. J Orthop Trauma. 2008;22(9):589-594.

13. Antapur P, Mahomed N, Gandhi R. Fractures in the elderly: when is hip replacement a necessity?. Clin Interv Aging. 2011;6:1-7.

14. Flegal KM, Kruszon-Moran D, Carroll MD, Fryar CD, Ogden CL. Trends in obesity among adults in the United States, 2005 to 2014. JAMA. 2016;315(21):2284-2291.

15. Porter SE, Graves ML, Maples RA, Woodall J Jr, Wallace JG, Russell GV. Acetabular fracture reductions in the obese patient. J Orthop Trauma. 2011;25(6):371-377.

16. Uppot RN. Impact of obesity on radiology. Radiol Clin North Am. 2007;45(2):231-246.

17. Yanch JC, Behrman RH, Hendricks MJ, McCall JH. Increased radiation dose to overweight and obese patients from radiographic examinations. Radiology. 2009;252(1):128-139.

18. Gettys FK, Russell GV, Karunakar MA. Open treatment of pelvic and acetabular fractures. Orthop Clin North Am. 2011;42(1):69-83, vi.

19. Brunette DD. Resuscitation of the morbidly obese patient. Am J Emerg Med. 2004;22(1):40-47.

20. Falchi M, Rollandi GA. CT of pelvic fractures. Eur J Radiol. 2004;50(1): 96-105.

21. Durkee NJ, Jacobson J, Jamadar D, Karunakar MA, Morag Y, Hayes C. Classification of common acetabular fractures: radiographic and CT appearances. AJR Am Jo Roentgenol. 2006;187(4):915-925.

22. O'Toole RV, Cox G, Shanmuganathan K, et al. Evaluation of computed tomography for determining the diagnosis of acetabular fractures. $J$ Orthop Trauma. 2010;24(5):284-290.

23. Sinatra PM, Moed BR. CT-generated radiographs in obese patients with acetabular fractures: can they be used in lieu of plain radiographs?. Clin Orthop Relat Res. 2014;472(11):3362-3369.

24. Morris BJ, Richards JE, Guillamondegui OD, et al. Obesity increases early complications after high-energy pelvic and acetabular fractures. Orthopedics. 2015;38(10):e881-e887.

25. Suzuki T, Morgan SJ, Smith WR, Stahel PF, Gillani SA, Hak DJ. Postoperative surgical site infection following acetabular fracture fixation. Injury. 2010;41(4):396-399.
26. Li Q, Liu P, Wang G, et al. Risk factors of surgical site infection after acetabular fracture surgery. Surg Infect (Larchmt). 2015;16(5):577-582.

27. Russell GV Jr, Nork SE, Chip Routt ML Jr. Perioperative complications associated with operative treatment of acetabular fractures. J Trauma. 2001;51(6):1098-1103.

28. Sagi HC, Dziadosz D, Mir H, Virani N, Olson C. Obesity, leukocytosis, embolization, and injury severity increase the risk for deep postoperative wound infection after pelvic and acetabular surgery. J Orthop Trauma. 2013;27(1):6-10.

29. Lawyer TJ, Jankowski J, Russell GV, Stronach BM. Prevalence of post-traumatic osteoarthritis in morbidly obese patients after acetabular fracture fixation. J Long Term Eff Med Implants. 2014;24(2-3):225-231.

30. Mourad WF, Packianathan S, Shourbaji RA, et al. The impact of class III (morbid) obesity on heterotopic ossification outcomes. Pract Radiat Oncol. 2012;2(3):e1-e6.

31. Vincent HK, Haupt E, Tang S, et al. Perioperative and acute care outcomes in morbidly obese patients with acetabular fractures at a Level 1 trauma center. J Orthop. 2014;11(2):58-63.

32. Finkelstein EA, Fiebelkorn IC, Wang G. National medical spending attributable to overweight and obesity: how much, and who's paying? Health Aff (Millwood). 2003;Suppl Web Exclusives:W3-219-26.

33. Russell GV, Pierce CW, Nunley L. Financial implications of obesity. Orthop Clin North Am. 2011;42(1):123-127, vii.

34. Wellen KE, Hotamisligil GS. Inflammation, stress, and diabetes. J Clin Invest. 2005;115(5):1111-1119.

35. Hossain P, Kawar B, El Nahas M. Obesity and diabetes in the developing world a growing challenge. $N$ Engl J Med. 2007;356(3):213-215.

36. Wild S, Roglic G, Green A, Sicree R, King H. Global prevalence of diabetes: estimates for the year 2000 and projections for 2030. Diabetes Care. 2004;27(5):1047-1053.

37. DeMaria EJ, Carmody BJ. Perioperative management of special populations: obesity. Surg Clin North Am. 2005;85(6):1283-1289, xii.

38. Shenkman Z, Shir Y, Brodsky JB. Perioperative management of the obese patient. Br J Anaesth. 1993;70(3):349-359.

39. Belzberg H, Wo CC, Demetriades D, Shoemaker WC. Effects of age and obesity on hemodynamics, tissue oxygenation, and outcome after trauma. J Trauma. 2007;62(5):1192-2000.

40. Ray CS, Sue DY, Bray G, Hansen JE, Wasserman K. Effects of obesity on respiratory function. Am Rev Respir Dis. 1983;128(3):501-506.

41. Biring MS, Lewis MI, Liu JT, Mohsenifar Z. Pulmonary physiologic changes of morbid obesity. Am J Med Sci. 1999;318(5):293-297.

42. Kahn SE, Hull RL, Utzschneider KM. Mechanisms linking obesity to insulin resistance and type 2 diabetes. Nature. 2006;444(7121): 840-846.

43. Sellmeyer DE, Civitelli R, Hofbauer LC, Khosla S, Lecka-Czernik B, Schwartz AV. Skeletal metabolism, fracture Risk, and fracture outcomes in type 1 and type 2 diabetes. Diabetes. 2016;65(7):1757-1766.

44. Stryker LS. Modifying risk factors: strategies that work diabetes mellitus. J Arthroplasty. 2016;31(8):1625-1627.

45. Adams JP, Murphy PG. Obesity in anesthesia and intensive care. $\mathrm{Br} J$ Anaesth. 2000;85(1):91-108.

46. Salama W, Mousa S, Khalefa A, et al. Simultaneous open reduction and internal fixation and total hip arthroplasty for the treatment of osteoporotic acetabular fractures. Int Orthop. 2017;41(1):181-189.

47. Jauregui JJ, Clayton A, Kapadia BH, Cherian JJ, Issa K, Mont MA. Total hip arthroplasty for acute acetabular fractures: a review of the literature. Expert Rev Med Devices. 2015;12(3):287-295.

48. De Bellis UG, Legnani C, Calori GM. Acute total hip replacement for acetabular fractures: a systematic review of the literature. Injury. 2014;45(2): 356-361.

49. Rothman KJ. BMI-related errors in the measurement of obesity. Int J Obes (Lond). 2008;32(Suppl 3):S56-S59.

50. Neville AL, Brown CV, Weng J, Demetriades D, Velmahos GC. Obesity is an independent risk factor of mortality in severely injured blunt trauma patients. Arch Surg. 2004;139(9):983-987.

51. Brown CV, Neville AL, Rhee P, Salim A, Velmahos GC, Demetriades D. The impact of obesity on the outcomes of 1,153 critically injured blunt trauma patients. J Trauma. 2005;59(5):1048-1051. 
52. Lazar MA, Plocher EK, Egol KA. Obesity and its relationship with pelvic and lower-extremity orthopedic trauma. Am J Orthop (Belle Mead NJ). 2010;39(4):175-182.

53. Ciesla DJ, Moore EE, Johnson JL, Burch JM, Cothren CC, Sauaia A. Obesity increases risk of organ failure after severe trauma. J Am Coll Surg. 2006;203(4):539-545.
54. Hoffmann M, Lefering R, Gruber-Rathmann M, Rueger JM, Lehmann W; Trauma Registry of the German Society for Trauma Surgery. The impact of BMI on polytrauma outcome. Injury. 2012;43(2):184-188.

55. Childs BR, Nahm NJ, Dolenc AJ, Vallier HA. Obesity is associated with more complications and longer hospital stays after orthopedic trauma. J Orthop Trauma. 2015;29(11):504-509.

\section{Publish your work in this journal}

Orthopedic Research and Reviews is an international, peer-reviewed, open access journal that focusing on the patho-physiology of the musculoskeletal system, trauma, surgery and other corrective interventions to restore mobility and function. Advances in new technologies, materials, techniques and pharmacological agents are particularly

\section{Dovepress}

welcome. The manuscript management system is completely online and includes a very quick and fair peer-review system, which is all easy to use. Visit http://www.dovepress.com/testimonials.php to read real quotes from published authors. 